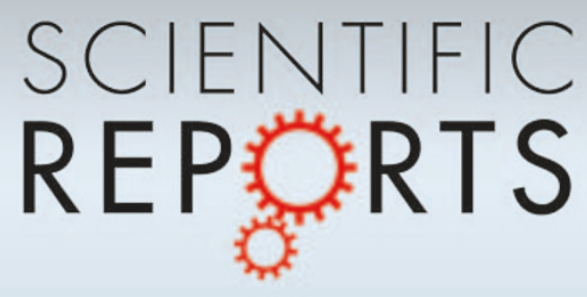

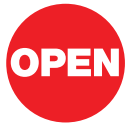

SUBJECT AREAS:

GENERAL PHYSICS

STATISTICAL PHYSICS, THERMODYNAMICS AND NONLINEAR DYNAMICS

INFORMATION THEORY AND COMPUTATION

STATISTICS

Received 16 February 2012

Accepted

19 March 2012

Published

5 April 2012

Correspondence and requests for materials should be addressed to T.P. (mail@tobiaspreis. de; preis@bu.edu)

* These authors contributed equally to this work.

\section{Quantifying the Advantage of Looking Forward}

\author{
Tobias Preis ${ }^{1,2,3 *}$, Helen Susannah Moat ${ }^{4,5 *}$, H. Eugene Stanley ${ }^{1 *} \&$ Steven R. Bishop ${ }^{4 *}$
}

'Department of Physics, Boston University, 590 Commonwealth Avenue, Boston, Massachusetts 022 15, USA, ${ }^{2}$ Chair of Sociology, in particular of Modeling and Simulation, ETH Zurich, Clausiusstr. 50, 8092 Zurich, Switzerland, ${ }^{3}$ Media Laboratory, Massachusetts Institute of Technology, 20 Ames St, Cambridge, Massachusetts 02139, USA, ${ }^{4}$ Department of Mathematics, UCL, Gower Street, London, WCIE 6BT, UK, ${ }^{5}$ Centre for Advanced Spatial Analysis, UCL, 90 Tottenham Court Road, London, WIT 4TJ, UK.

We introduce a future orientation index to quantify the degree to which Internet users worldwide seek more information about years in the future than years in the past. We analyse Google logs and find a striking correlation between the country's GDP and the predisposition of its inhabitants to look forward.

ecent years have witnessed a revolution in the social sciences. Mammoth amounts of data are now being generated through society's extensive interactions with technological systems, automatically documenting collective human behaviour in a previously unimaginable fashion ${ }^{1-3}$. Analysis of such "big data" opens up new opportunities for a more precise and extensive quantification of real world social phenomena that was difficult to attain using complicated and expensive surveys and laboratory experiments alone.

A particularly fruitful area of research has focused on the analysis of Internet user search queries, as logged by search engines such as Google. Strong links have been found between changes in the information users are seeking online and events in the real world, ranging from reports of flu infections across the USA ${ }^{4}$ to the trading volume in the US stock markets ${ }^{5}$.

Interdependencies among social entities distributed worldwide are growing, a development with repercussions for the way our world works ${ }^{6}$. However, research based on search engine queries has to date offered insight into behaviour only within distinct linguistic silos, due to its reliance on keyword analysis, and the thousands of different languages spoken in our linguistically varied world.

\section{Results}

In this study, we present a cross-country analysis of search engine queries, and demonstrate a strong link between behaviour online and real world economic indicators. By considering searches for years represented in Arabic numerals, an almost ubiquitous written representation, we can evaluate worldwide interest in years in the future (such as "2013") and years in the past (such as "2011"). These representations have previously been considered in an investigation of a large corpus of text from books, where analysis suggested that authors' interest in the past has decreased over time ${ }^{7}$. Here, we compare the predisposition of Internet users in different countries to look more to the future, or more to the past. We find that the online "future orientation" of a country is strongly correlated with the country's per capita gross domestic product (GDP).

For these reasons, we calculate the ratio of the volume of searches made for the coming year (represented in Arabic numerals) to the volume of searches for the previous year and call this value the future orientation index (Fig. 1a). We compute the future orientation index for each of 45 countries with data from the search engine Google for users located in the country in question from the year 2010, using the search terms "2009" and "2011". The Google Trends service from which these data are taken does not report absolute search volumes, but scales these volumes according to the average search volume for the first term in each data request. For each country, we therefore request the search volumes for all terms simultaneously, to ensure that these volumes are comparable. We compare the future orientation index to the country's per capita GDP, calculated on a purchasing power parity basis, which we retrieve from the CIA World Factbook which provides figures as of 1 July 2010. Our analysis considers countries for which both Google Trends and the CIA World Factbook provide data, and to reduce noise excludes countries with fewer than five million Internet users, for which few search data are available. We uncover a strong tendency for countries in which Google users enquire more about the future to exhibit a larger per capita GDP (Fig. 1b; Pearson correlation coefficient $r=0.78, d f=43, p<0.001$ ). We investigate the robustness of the future orientation index by considering search data from earlier years. The ratio calculation that this index is based 

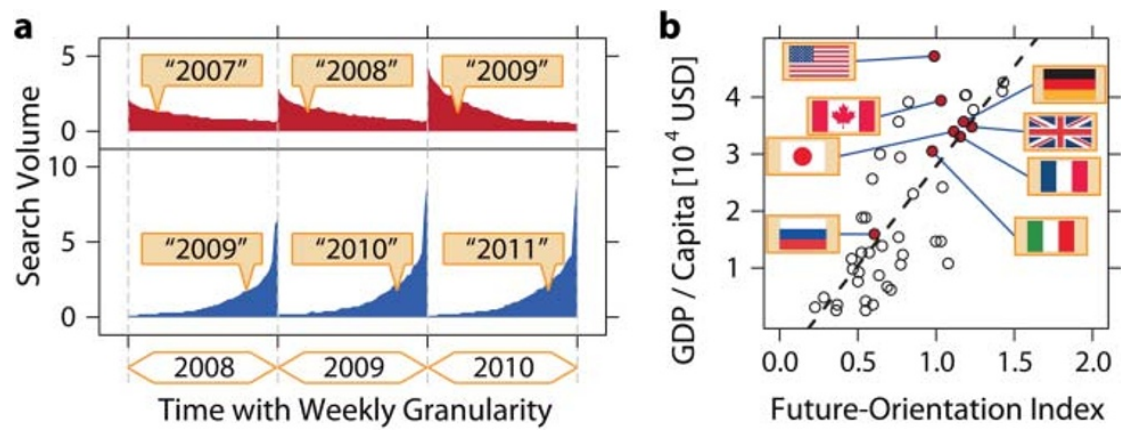

Future-Orientation Index

Figure $1 \mid$ The future orientation index, and its correlation with per capita GDP. (a) The frequency with which Google users worldwide search for information about the previous year (in red) and the following year (in blue). Data are plotted for each of 52 weeks per year. The future orientation index for a given year (e.g., 2010) is calculated as the ratio of the total number of searches for the following year ("2011") to the total number of searches for the previous year ("2009"). (b) The future orientation index for 45 countries based on searches in 2010, compared with per capita GDP. We demonstrate a strong tendency for countries in which Google users enquire more about the future to possess a larger per capita GDP (Pearson correlation coefficient $r=0.78, d f=43, p<0.001)$.

on allows it to absorb any overall increase or decrease in the volume of searches from year to year. We find similar relationships between the future orientation index and per capita GDP in 2010 for calculations of the index with search data from 2009, using the search terms "2008" and "2010" ( $r=0.64, d f=43, p<0.001)$, and for calculations of the index with search data from 2008 , using the search terms "2007" and "2009" ( $r=0.53, d f=43, p<0.001)$.

\section{Discussion}

In this study, we have introduced the future orientation index, which quantifies to what extent Internet users worldwide are seeking information about the future rather than the past. The analysis described here shows that the value of this index for 45 countries in 2010 is correlated with a key economic indicator, per capita GDP. Our results are consistent with the intriguing possibility that there is a relationship between the economic success of a country and the information seeking behaviour of its citizens online. We highlight two potential explanations for such a relationship. Firstly, these findings may reflect international differences in attention to the future and the past, where a focus on the future supports economic success. Secondly, these findings may reflect international differences in the type of information sought online, perhaps due to economic influences on available Internet infrastructure. We suggest that the future orientation index may be productively applied to further spatial and temporal divisions, and compared with further social and economic indicators, to help develop an Internet data driven image of worldwide society today.

1. King, G. Ensuring the Data-Rich Future of the Social Sciences. Science 331, 719 (2011).
2. Lazer, D. et al. Computational Social Science. Science 323, 721 (2009).

3. Vespignani, A. Predicting the Behavior of Techno-Social Systems. Science 325, 425 (2009).

4. Ginsberg, J. et al. Detecting influenza epidemics using search engine query data. Nature 457, 1012 (2009).

5. Preis, T., Reith, D. \& Stanley, H. E. Complex dynamics of our economic life on different scales: insights from search engine query data. Phil. Trans. R. Soc. A 368, 5707 (2010).

6. Schweitzer, F. et al. Economic Networks: The New Challenges. Science 325, 422 (2009).

7. Michel, J.-B. et al. Quantitative Analysis of Culture Using Millions of Digitized Books. Science 331, 176 (2011).

\section{Acknowledgements}

We retrieved search volume data by accessing the Google Trends website (http:// www.google.com/trends) on February 1, 2012.

GDP per capita data were retrieved from the CIA World Factbook (https://www.cia.gov/ library/publications/the-world-factbook/) on February 1, 2012.

This work was partially supported by the German Research Foundation Grant PR 1305/1-1 (to T.P.) and the National Science Foundation (to H.E.S.).

\section{Author contributions}

T.P., H.S.M., H.E.S. and S.R.B. performed analyses, discussed the results, and contributed to the text of the manuscript.

\section{Additional information}

Competing financial interests: The authors declare no competing financial interests.

License: This work is licensed under a Creative Commons

Attribution-NonCommercial-ShareAlike 3.0 Unported License. To view a copy of this license, visit http://creativecommons.org/licenses/by-nc-sa/3.0/

How to cite this article: Preis, T., Moat, H.S., Stanley, H.E. \& Bishop, S.R. Quantifying the Advantage of Looking Forward. Sci. Rep. 2, 350; DOI:10.1038/srep00350 (2012). 